\title{
RESEARCH PAPER \\ DOES HIGH SCHOOL ELECTIVE MATHEMATICS HAVE ANY EFFECT ON PERFORMANCE IN UNIVERSITY ECONOMICS IN GHANA?
}

\author{
H. Yusif \\ Department of Economics, KNUST, Kumasi. Ghana \\ Author's email:hadraty@yahoo.co.uk
}

\begin{abstract}
The Department of Economics has one of the highest rates of students' failures, repetition and withdrawals in the Kwame Nkrumah University of Science and Technology (KNUST), Kumasi. In the 2011/2012 and 2012/2013 academic years 35.8\% and 30.6\% of the 232 and 301 final year students respectively could not graduate. This concern has been attributed primarily to the low mathematical ability of the affected students. Consequently, university authorities in the 2013/2014 academic year made senior high school (SHS) elective mathematics a central requirement for students who intend pursuing economics as major. Really, this policy was not based on any systematic study conducted in the country. This paper contributes to existing literature by examining the impact of SHS elective mathematics on the performance of economics major students in KNUST. Two cohorts of students who entered KNUST in the 2009/2010 and 2010/2011 academic years were used for this study. Ordered probit was fitted to individual data collected from 334 respondents (142 females and 192 males) who graduated in June, 2013 and June 2014 respectively. The results show that SHS elective mathematics has significant positive influence on economics students' academic performance in the KNUST. It was also found that performance in mathematics related courses in the first year and cumulative weighted average at the end of year one has significant and direct influence on the performance of students in subsequent years. The findings thus confirm that mathematical ability both at the SHS level and in the university is positively correlated with overall performance in university economics.
\end{abstract}

Keywords: Academic performance, University, Economics, Students, Mathematics

\section{INTRODUCTION}

Researchers have investigated the effect of mathematics on the performance of students in economics (Reid, 1993; Myatt and Waddell, 1990; Kassens Uhl and Fleming, 2007; Hoag and Benedict, 2010). The general conclusion appears to be that mathematics skills acquired in high school have strong link with good performance in economics. Certainly, economics courses are in general difficult for the average 
student (Hoag and Benedict, 2010, Lagerlof and Seltzer, 2008). Accordingly, in many universities worldwide, economics students require sufficient knowledge of mathematics, especially in algebra, calculus, trigonometry, and graphs to enable them complete successfully economics programmes.

In Ghana, Senior High School (SHS) students who wish to pursue economics as major in public universities are required to have a good knowledge of mathematics. In fact, under the 64-7-3 old educational system (i.e. 6 years of primary school, 4 years of middle school, 7 years for General Certificate of Education Ordinary and Advanced levels, and 3 years in university) from 1960-1993, applicants who wanted to pursue BA Economics were required to have good scores in Ordinary Level Modern Mathematics (at least grade 4) plus good pass in GCE Advanced Level economics. Similarly in 1993, the current educational system of 6-3-3 -4 (6 years in primary school, 3 years in junior high school, 3 years in senior high school, 4 years in university) that was introduced required applicants who intend pursuing BA in Economics to have a good pass in Core Mathematics (at least credit-grade $\mathrm{C}$ or B3) plus at least credit pass (grade $\mathrm{C}$ or B3) in Economics among the six subjects required to qualify for admission.

These requirements notwithstanding, the Department of Economics has one of the highest rates of failure and withdrawal in KNUST. In the 2011/2012 and 2012/2013 academic years $35.8 \%$ and $30.6 \%$ of the 232 and 301 final year students respectively did not graduate. Some were withdrawn and others had to repeat. University authorities and parents are worried about the high rates of failure and withdrawals. To address this issue, the university authorities modified the admission requirement for the BA Economics programme. According to the new policy applicants seeking for admission into the BA Economics programme must have a good pass in elective mathematics (grade C or B3) in addition to good pass (grade C or B3) in SHS economics, English language, integrated science and core mathematics. Thus, the applicant must have good pass in both core Mathematics and elective Mathematics (KNUST, 2011). This requirement became operational with effect from the 2013/2014 academic year.

The basis of this policy might be due to the fact that students who take elective mathematics in addition to the compulsory core mathematics do more mathematics than those who did not and since the mathematics content in economics at the university is high, students with high school elective mathematics are likely to understand economic theories and models better. They might be able to improve their advanced technical skills as well as critical thinking skills faster and thus perform better in the analysis of multifaceted economic issues in sub-Sahara Africa. In sum, mathematics maturity and understanding help students become better overall learners (Hoag and Benedict, 2010).

Indeed, the relationship between mathematics ability and subsequent performance in economics courses has been investigated in the OECD countries (Ballard and Johnson, 2004; Hoag and Benedict, 2010; Lagerlöf and Seltzer, 2008; Reid,1993; Siegfried et al. 1996; Anderson et al., 1994). However, the results are inconsistent across the studies and do not provide economics departments, especially in sub-Sahara Africa with strong directions regarding the influence of mathematics on the performance of economics students in the university.

Yet, no study has explored the influence of mathematics on the performance of university students in undergraduate economics in Ghana. This paper proposes to provide evidence on the effect of elective mathematics on the success of undergraduate economics students in the KNUST. The paper focuses on the long run performance of students i.e. the Cumulative Weighted Average (CWA) in the final year. This study seeks to provide scientific evidence to guide the selection of suitable high school 
graduates for the economics programme in Ghanaian universities, especially KNUST that would reduce withdrawals and failures. Again, the study could influence decisions as to whether SHS students admitted into the BA Economics programme and do not have adequate pre-university preparation in mathematics could be given opportunity to do some remedial courses in mathematics before registration.

\section{Review of relevant literature}

In the industrialized countries some researchers have investigated the effect of mathematics on the academic performance of students in the university. Using data from Midwestern University, Hoag and Benedict (2010) applied the ordered probit model to a sample size of 2,823 students from 2002 to 2006 . They reported that students who have completed mathematics class for majors/educators have a higher average probability of receiving grade $\boldsymbol{A}$ of 12.6 percentage points, and a 12.2 higher average probability of receiving grade $\boldsymbol{B}$, compared to students in elementary and intermediate algebra. They argue that mathematics maturity at the high school will help students perform better in their first economics course in the university.

Ballard and Johnson (2004), used data from a sample of 1,462 students to investigate the effect of mathematics skills on performance in principles of microeconomics. They reported that quantitative skills are very important forsuccess in introductory economics. The mathquiz score is positively and significantly related to student performance.

Similarly, Lagerlöf and Seltzer (2008) examined the effect of remedial mathematics which was introduced by the Economics Department of Royal Holloway, University of London, for students who had not studied mathematics beyond age 16 or had performed poorly in secondary school mathematics. Lagerlöf and Seltzer (2008) found that the level of and performance in mathematics courses taken prior to university have strong predictive power on students' performance in a range of economics courses. However, remedial mathematics had no effect on performance in Principles of Economics. Reid (1993) showed that the grade students earn in a college principles course is affected in a statistically significant and positive way by having taken a mathematics class in their senior year in high school.

Brasfield et al. (1993) studied the impact of high school economics on performance in college Principles of Economics. The mathematics sequence variable, MA220, was positive and significant in the macroeconomics regression but not the microeconomics regression. One possible explanation for this result was that principles of macroeconomics typically incorporates more algebra, especially in national income determination models than does microeconomics.

Hoag and Benedict (2010), reported that the effect of the ACT math sub scores indicated that students who received higher scores in elementary algebra, college algebra, or trigonometry and geometry had a higher probability of receiving $\mathrm{A}$ and $\mathrm{B}$ grades in their economics courses. Again, the higher the level of ability in mathematics, e.g., trigonometry and geometry, the more likely the student would perform well in economics. Taking college-level business calculus or higher level mathematics has an economically and statistically significant impact on performance in one's economics class.

In contrast, Siegfried et al. (1996) reported that about half of the students taking principles of economics have had a college level calculus course before they took economics. It is clear that success in economics can be achieved without calculus, but that calculus is widely seen as a valuable tool for many economics students. Anderson et al. (1994) examined the predictors of academic success in principles of economics in a class that was essentially a yearlong principles class. The dependent variable was the final grade. The independent variables 


\section{Yusif}

included how the student performed in various high school classes (this is a Canadian study, so the authors create an index using data on the best six classes in the students' 13th year of school). This high school grade index was statistically significant and positive. The subject areas were represented by binary variables indicating if the student took the class in their final year of high school and a second variable representing their grade in that class. The authors controlled for three different mathematics classes: algebra, functions, and calculus. These mathematics variables had a negative coefficient, but were not statistically significant. The mathematics grade had a positive coefficient, but was not statistically significant. However, joint tests on the dummy variable and grade for each mathematics class indicated that neither algebra nor functions had an impact, but that calculus did.

From the discussion above, it is obvious that the effect of mathematics ability on subsequent performance in economics courses has been investigated by researchers. However, the results are inconsistent across studies and do not provide economics departments with strong directions regarding the type and sequence of mathematics and economics courses (Hoag and Benedict, 2010).

\section{DATA AND VARIABLE DESCRIPTION}

The data were derived from two cohorts of economics major students, who entered KNUST in 2009 and in 2010. They graduated in June, 2013 and in June 2014 respectively. These groups of students were not affected by the entry requirement that an applicant must have a good pass in elective mathematics in addition to the core mathematics. The dependent variable, which measures a student's academic performance, is the cumulative weighted average (CWA) a student graduated with from the university after the four year period. At KNUST the CWA ranges from 0 to 100 . It is measured by multiplying the score in a particular course by the credit hours. This is summed up for all the courses that a student offered for the period and divided by the total credit hours registered during the period. To ensure there is no bias I relied on the CWA obtained from the records of students kept in the office of the Examinations Officer at the Department of Economics. Certainly, students tend to overstate their GPA (Maxwell and Lopus, 1994; Ballard and Johnson, 2004). This is true for some weak students who might not want their class mates to know their academic status. They are likely to write inaccurate GPA or CWA when filling the questionnaires.

The explanatory variables were derived from a survey completed by final year economics major students in the second semesters of the 2012/2013 and 2013/2014 academic years. The sample population consisted of 334 students. The explanatory variables included SHS elective mathematics, WASSCE score, first year CWA, first year mathematics (average of Mathematics for Economists I \&II and Statistical Methods I \& II) age, age squared, and gender. Age squared was included to take care of nonlinearity.

The SHS elective mathematics (EMATH) is a measure of mathematics ability or preparation, whilst the WASSCE score is a measure of students' ability and high school inputs. A large fraction of studies that have investigated the effect of mathematics on students' academic performance attempt to control for students' mathematics abilities by including a dummy variable for whether students have taken calculus or by including a measure of mathematics aptitude (Ballard and Johnson, 2004).

Year One CWA (YR1CWA) is a university input and measures student preparedness for university education. Gender and age are students' characteristics variables and were included to test whether being male and also being a mature student (25 years or more at university entry) have effects (positive or negative), on performance in economics. Gender (male or female) is a categorical variable whilst age is a continuous variable. Age squared is 
Impact of SHS elective mathematics on economics major students... 102

also included to capture non-linear effects. A brief description of the variables is shown in Table 1.

\section{Econometric Model}

Borrowing from previous studies (Brasfield et al., 1993; Butler et al., 1994; Hoag and Benedict, 2010); this paper measures the impact of high school elective mathematics on performance in university economics using an ordered probit model. The ordered probit is employed since the dependent variable is a four-class outcome variable. The model is specified as

$y_{i}^{*}=x_{i}^{\prime} \beta+\varepsilon_{i}, \varepsilon_{i} \sim N(0,1)$

Where the latent continuous variable, $y^{*}$, represents grading scale of student's cumulative weighted average (CWA), which is used to determine how well a student is performing or performed. The CWA is a linear combination Where $U(0), U(1), U(2)$ and $U(3)$ are the mini-

of some predictors, $\boldsymbol{x}$, plus a disturbance term, mum thresholds underlying the CWA grading $\varepsilon$, which has a standard normal distribution. But, $y^{*}$ is unobserved, what is observed is the ordinal variable (final CWA attained by each student) and represented by $y_{i}$ which takes on coded values $0,1,2$, and 3 . In this, $\mathbf{0}$ is Pass, 1 is Second Class Lower Division, 2 is Second Class Upper Division and $\mathbf{3}$ is First Class.

For each student, it is assumed there is a relationship between the underlying CWA scale $\left(y^{*}\right)$ and the observed final CWA $\left(y_{i}\right)$ he/she achieved. This relationship follows the scheme:

$$
\begin{aligned}
y_{i}=j \Leftrightarrow & \mu_{j-1} \leq y_{i}^{*}<\mu_{j,} \\
& y_{i=} 0 \text { if } y_{i}{ }^{*}<U(0) \\
& y_{i}=1 \text { if } U(0)<y_{i}{ }^{*} \leq U(1) \\
& y_{i=} \text { if } U(1)<y_{i} \leq U(2) \\
& y_{i}=3 \text { if } U(2)<y_{i}
\end{aligned}
$$

\begin{tabular}{|c|c|}
\hline VARIABLE & DESCRIPTION \\
\hline \multicolumn{2}{|l|}{ Dependent Variable } \\
\hline CWA & $\begin{array}{l}\text { Class a student attained on graduation. Coded } 0 \text { for Pass, } 1 \text { for Second Class } \\
\text { Lower, } 2 \text { for Second Class Upper, and } 3 \text { for First Class. }\end{array}$ \\
\hline Explanatory Variable & \\
\hline GENDER & Dummy variable, 1 if male and 0 female \\
\hline AGE & Continuous variable indicating age of student upon first entry in KNUST \\
\hline AGE SQUARED & Included to take care of nonlinearity \\
\hline EMATH & $\begin{array}{l}\text { Dummy variable, } 1 \text { for student who took elective math at SHS and } 0 \text { other- } \\
\text { wise }\end{array}$ \\
\hline WASSCE & Continuous variable indicating final SHS examination aggregate score \\
\hline WASSCE SQUARED & Included to take care of nonlinearity \\
\hline ADMIPATH-Regular & Dummy variable, 1 if regular and 0 otherwise \\
\hline ADMIPATH-Feepay & Dummy variable, 1 if fee paying and 0 otherwise \\
\hline ADMIPATH-Mature & Dummy variable, 1 if mature and 0 other \\
\hline ADMIPATH-Lesend & Dummy variable, 1 if less endowed and 0 otherwise \\
\hline YR1 CWA & First year cumulative weighted average of a student \\
\hline YR1MATH & $\begin{array}{l}\text { Average grade for first year university mathematics courses- Mathematics } \\
\text { for Economists I\&II and Statistical Methods I\&II }\end{array}$ \\
\hline
\end{tabular}

Table 1: Description of variables 


\section{Yusif}

scale necessary to obtain Pass, Second Class Lower Division, Second Class Upper Division or First Class respectively.

\section{RESULTS AND DISCUSSION}

Table 2 presents the ordered probit results. The principal interest is the elective maths (Emath) variable. The results in Table 2 show that elective maths is significant at the 0.000 level and has a positive influence on economics students' academic performance in the KNUST. This finding is consistent with past studies. For example Reid (1993) found that the grade students earn in a college principles course is affected in a statistically significant and positive way by having taken mathematics class in their senior year in high school. Kassens Uhl and Fleming (2007) reported that students with better mathematics skills performed better in their economics classes. But just as Hoag and Benedict (2010) also reported, this study did not investigate whether the impact comes from the performance in the mathematics course or the skills the candidate brings to the university. Indeed, this is an area that future research on economics of education in Ghana could address.

Also, the results reveal a significant and positive university mathematics (Umath) effect on the performance of economics major students in subsequent years in the KNUST. The university mathematics variable (Umath) is the average score of first year mathematics courses Math 153/154 Statistical Methods and ECON 153/154: Mathematics for Economists. Similarly, a student's first year CWA, which captures university inputs, ability, and preuniversity preparation, has a significant and direct influence on the performance of students.

The high school score variables capture students' ability in this study. It is positively correlated with performance in subsequent years. The coefficient has negative sign because the bigger the WASSCE aggregate the lower the ability. This finding appear not to support Harackiewicz et al. (2002) who argued that ability has direct effect on performance in the first year but it reduces in subsequent years.

Table 2: Ordered probit results (95\% significance level)

\begin{tabular}{lllll}
\hline Variable & Coefficient & Std Err. & $\mathbf{z}$ & $\mathbf{P}>|\mathbf{z}|$ \\
\hline Age & -0.06439 & 0.02337 & -2.75 & 0.006 \\
WASSCE & -0.20969 & 0.03489 & -6.01 & 0.000 \\
Emath & 0.6568 & 0.24990 & 2.63 & 0.009 \\
Umath & 0.05531 & 0.012796 & 4.32 & 0.000 \\
Y1CWA & 0.09447 & 0.016987 & 5.56 & 0.000 \\
Male & 0.13977 & 0.194299 & 0.72 & 0.472 \\
Feepay & -1.2696 & 0.4300 & -2.95 & 0.003 \\
Mature & -1.03978 & 0.2967 & -3.50 & 0.000 \\
Lessend & 1.2125 & 0.48648 & 2.49 & 0.013 \\
Regular & -0.2022 & 0.2850 & -0.71 & 0.478 \\
Cut 1 & 2.1922 & & & \\
Cut 2 & 3.7310 & & & \\
Cut 3 & 6.2168 & & & \\
Number of observations 341 & & & \\
Log-likelihood & -133.55 & & & \\
LR chi (10) & 555.31 & & & \\
Pseudo R2 & 0.6752 & & & \\
\hline
\end{tabular}


The gender variable has the correct sign but it is statistically insignificant. This finding supports Brasfield et al. (1993) who found the gender variable to be insignificant and recommended further investigation into the variable. However, the present paper contradicts the findings of Siahaan et al. (2014). Siahaan et al. (2014) studied the educational attainments of immigrant children in the USA and concluded that females receive higher educational attainment than males.

Another variable of interest is the admission path. The results reveal that admission path has effect on outcomes. For example the coefficients of the fee paying variable (Feepay) and mature student (Mature) variable have negative signs; suggesting that being fee paying student or mature student has negative effect on performance. These appear to reflect the reality in the Ghanaian context. First, fee paying students are applicants who had the basic qualification for university entry but could not meet the cutoff point.

They were admitted because they were prepared to pay full fees. With regard to mature students, usually they are more than 25 years of age and some of them are married and also working. Because of these socio-economic responsibilities, they are unlikely to spend more time on their books which tends to impact negatively on their performance.

\section{CONCLUSION}

This paper has examined the impact of high school elective mathematics on performance in university economics using data from KNUST in Ghana. Questionnaires were administered and ordered probit model was fitted to individual level data obtained from 334 respondents; comprising two cohorts of economics major students, who entered KNUST in 2009 and in 2010 academic years respectively. The following major findings emerged. First, it was found that taking elective mathematics in the SHS has significant positive impact on performance in university economics in KNUST. This appears to support the basic requirement that economics major students in KNUST must have a SHS elective mathematics.

It was also found that performance in mathematics related courses like ECON 153/154: Mathematics for Economists I \&II and MATH 153/154: Statistical Methods I \& II has significant and positive impact on students' outcome in economics. The results also reveal that the fee paying and mature students' variables have negative influence on performance.

This paper thus concludes that additional exposure to mathematics in the SHS has significant positive impact on student academic performance in economics in the KNUST. That, students with limited mathematics background could be offered additional mathematics courses, in algebra, calculus, geometry, and trigonometry etc to enable them improve their mathematics skills. These students should include fee paying students and mature students.

This study has investigated the effect of taking elective mathematics in the SHS on performance in university economics. The sample consisted of students who took elective mathematics in the SHS and those who did not. From the regression results, taking elective mathematics has significant positive influence on the performance of economics students in university. It is recommended that, in KNUST, further research should examine the extent to which performance in SHS elective mathematics affects students' academic outcomes in university economics. Currently, elective mathematics is mandatory for all applicants who intend pursuing economics as major course in KNUST. Such a study is needed to enable economics departments and university authorities in Ghana, have profound knowledge regarding the influence of elective mathematics on performance of economics students.

\section{REFERENCES}

Anderson, G., Benjamin, D. and Fuss, M. A. (1994). The determinants of success in univer- 
105 Yusif

sity introductory economics classes. Journal of Economic Education, 25(2): 99-119.

Ballard, C. and Johnson, M. (2004). Basic math skills and performance in an introductory economics class. Journal of Economic Education, 25(4): 3-23.

Brasfield, D. W., Harrison, D. E. and McCoy, J. P. (1993).The Impact of High School Economics on the College Principles of Economics Course. Journal of Economic Education, 24(2): 99-111.

Butler, J. S., Aldrich F. T., and Sigfried, J. J. (1994). Does More Calculus Improve Student Learning in Intermediate Micro and Macro Economic Theory? The American Economic Review, Papers and Proceedings, 84(2): 206-210

Harackiewicz, J. M., Barron, K. E., Tauer, J. M. and Elliot, A. J. (2002). Predicting success in college: A longitudinal study of achievement goals and ability measures as predictors of interest and performance from freshman year through graduation. Journal of Education Psychology, 94 (3): 562-575.

Hoag, J. and Benedict, M. E. (2010). What influence does mathematics preparation and performance have on performance in first economics classes? Journal of Economics and Economic Education, 11 (1): 19-42.

KassensUhl, A. and Fleming, G. (2007). Pre dicting Gen Y's Performance in Principles of Economics Courses: A Preliminary Examination. Virginia Economic Journal, 12: 1 -22 .
KNUST (2011). Entry requirements and guidelines for selecting an undergraduate programme 2012-2013. University Printing Press, Kumasi.

Lagerlöf, J. and Seltzer, A. (2008). Do remedial mathematics courses help economics students? Accessed from http://www.voxeu.org/ article/do-remedial-mathematics-courseshelp-economics-students.downloaded 6th April, 2013.

Maxwell, N. L. and Lopus, J. S. (1994). The Lake Wobegon effect in student self-reported data. American Economics Association $\mathrm{Pa}-$ pers and Proceedings, 84(2): 201-205.

Myatt, A. and Waddell, C. (1990). An Approach to Testing the Effectiveness of the Teaching and Learning of Economics in High School. Journal of Economic Education, 21(3):355-363.

Reid, R. (1993). A Note on the Environment as a Factor Affecting Student Performance in Principles of Economics. Journal of Economic Education, 14(4):18-22.

Siahaan, F., Lee, D. Y. and Kalist, D. E. (2014). Educational attainment of children of immigrants: Evidence from the national longitudinal survey youth, Economics of Education Review, 38:1-8.

Siegfried, J. J., Saunders, P., Stinar, E. and Hao, Z. (1996). How is Introductory Economics taught in America? Economic Inquiry, 34 (1):182-192. 